\title{
REPRESENTAÇÕES SOCIAIS SOBRE INFORMAÇÃO E CONHECIMENTO NA EDUCAÇÃO A DISTÂNCIA: UM ESTUDO DE CASO NA UFMG
}

\author{
Sinay Santos Silva de Araujo ${ }^{\mathrm{i}}$ \\ Maria Aparecida Moura ${ }^{\text {ii }}$
}

\begin{abstract}
Resumo: Este artigo apresenta os conceitos de informação e conhecimento adotados por alunos, professores e tutores oriundos dos cursos de graduação na modalidade de educação a distância em Ciências Biológicas e Matemática da Universidade Federal de Minas Gerais (UFMG). As representações sociais foram sistematizadas no estudo que investigou a formação da cultura informacional na modalidade de educação a distância. Foram utilizadas como referencial teórico a Teoria das Representações Sociais e a técnica do Discurso do Sujeito Coletivo (DSC), desenvolvida por Lefevre e Lefevre. De acordo com as representações sociais dos sujeitos da pesquisa, a informação é a base para a construção do conhecimento e é compreendida como um fenômeno humano que se relaciona à produção de sentido. O conhecimento sistemático é compreendido como a informação que pode ser socialmente transmitida.
\end{abstract}

Palavras-chave: Representações sociais. Informação. Conhecimento. Discurso do Sujeito Coletivo.

\section{SOCIAL REPRESENTATIONS OF INFORMATION AND KNOWLEDGE ON THE DISTANCE EDUCATION MODALITY: A CASE STUDY AT UFMG}

\begin{abstract}
This article presents the concepts of information and knowledge adopted by undergraduates, professors and assistant teachers from the distance education in the undergraduate courses in Biological Sciences and Mathematics at Federal University of Minas Gerais (UFMG). The social representations were systematized in the study that investigated the formation of informational culture in the distance education modality. It was used as a theoretical framework the Social Representation Theory and the technique of CSD (Discourse of the Collective Subject) developed by Lefèvre and Lefèvre. According to the social representations of research subjects, information is the basis for the construction of knowledge and is understood as a human phenomenon that relates to the production of meaning. The systematic knowledge is the information that can be socially communicated.
\end{abstract}

Keywords: Social representations. Information. Knowledge. Discourse of the Collective Subject.

\footnotetext{
${ }^{i}$ Universidade Federal de Minas Gerais. sinayaraujo@hotmail.com.

ii Universidade Federal de Minas Gerais. mamoura@eci.ufmg.br.

Recebido em: 17/06/2011; aceito para publicação em: 26/03/2012.
} 


\section{INTRODUÇÃO}

As representações sociais são elementos simbólicos que os homens expressam mediante o uso de palavras e de gestos para explicitar o que pensam, demonstrar os seus sentimentos sobre uma determinada situação e formular opiniões acerca de determinado fato ou objeto. (PINHEIRO, 2008). As representações sociais investigam "como se formam e como funcionam os sistemas de referência que utilizamos para classificar pessoas e grupos e para interpretar os acontecimentos da realidade cotidiana." (ALVES-MAZZOTTI, 1994, p. 60). As representações sobre informação e conhecimento expressam as opiniões, os valores, as crenças que as pessoas adotam na composição desses conceitos. Essas representações são construídas a partir dos elementos culturais, sociais e históricos que permeiam o espaço social desses sujeitos.

\section{CULTURA INFORMACIONAL}

O conceito de cultura informacional apresentado neste artigo tem como base a concepção de cultura como um sistema simbólico composto por vários padrões “construídos pelos sujeitos em sociedade (palavras, conceitos, técnicas, regras, linguagens) pelos quais dão sentidos, produzem e reproduzem sua vida material e simbólica" (MARTELETO, 1995, p. 2), e de informação como "um conjunto estruturado de representações mentais e emocionais codificadas (signos e símbolos) e modeladas com/pela interação social.” (SILVA, 2006, p. $150)$.

Para Marteleto (1995, p. 2), “cultura e informação são conceitos/fenômenos interligados pela sua própria natureza". Para Geertz (1989, p. 37), a cultura pode ser "vista como um conjunto de mecanismos simbólicos para o controle do comportamento, fontes de informações extra-somáticas". Esses dois conceitossão, portanto, vistos como indissociáveis.

$\mathrm{Na}$ perspectiva antropológica, cultura é um sistema social que age seletivamente no meio ambiente explorando as possibilidades e limites do desenvolvimento humano. Estabelece uma dependência entre o sistema cultural de um determinado grupo social e a formação dos indivíduos desse grupo. Nesse sentido, "o homem é o resultado do meio cultural em que foi socializado. Ele é um herdeiro de um longo processo acumulativo, que reflete o conhecimento e a experiência adquirida pelas numerosas gerações que o antecederam" 
(LARAIA, 2001, p. 45). Assim, o comportamento dos indivíduos na sociedade depende de um processo de aprendizado chamado endoculturação.

Morin (1998, p. 23) argumenta que a cultura é a manifestação das representações, da consciência e do imaginário coletivo. "E, dispondo de seu capital cognitivo, a cultura institui as regras/normas que organizam a sociedade e governam os comportamentos individuais".

Assim, entende-se que a cultura informacional é um fenômeno social e humano, formado por um conjunto complexo e interligado de sistemas simbólicos, compostos por padrões, normas, valores, linguagens, técnicas, instruções que orientam as ações e as práticas informacionais dos sujeitos sociais em um determinado espaço social.

A partir dessa perspectiva, propõe-se que a constituição do conceito de cultura informacional envolva as seguintes abordagens: informacional, política, econômica, tecnológica, científica, educacional, cidadã e ética. O Quadro 1 apresenta a descrição dessas abordagens.

\begin{tabular}{|c|c|}
\hline Abordagens & Descrição \\
\hline acional & $\begin{array}{l}\text { "Refere-se aos conhecimentos que permitem que o sujeito possa } \\
\text { expressar sua cultura e pertencimento social, assim como as suas } \\
\text { necessidades informacionais através da interação com recursos e } \\
\text { dispositivos informacionais contemporâneos e históricos" (MOURA, } \\
\text { 2011, p. 54). }\end{array}$ \\
\hline Política & $\begin{array}{l}\text { Refere-se aos mecanismos de controle, divulgação e monopolização da } \\
\text { informação, como as políticas de acesso, custo e disponibilização, tanto } \\
\text { nos sistemas convencionais como nos sistemas digitais. }\end{array}$ \\
\hline Econ & $\begin{array}{l}\text { Refere-se à perspectiva econômica da informação, principalmente a } \\
\text { digital, na qual o uso dessa informação movimenta amplos e } \\
\text { diversificados mercados econômicos. (MOURA, 2011, p. 54). }\end{array}$ \\
\hline Tecn & $\begin{array}{l}\text { Refere-se às habilidades para manipular, analisar e reconstruir as } \\
\text { tecnologias da informação e comunicação que permeiam e interferem } \\
\text { na formação da cultura informacional de toda a sociedade. }\end{array}$ \\
\hline Cien 1 & $\begin{array}{l}\text { Refere-se à noção de ciência, enquanto processo de construção de } \\
\text { conhecimento sistematizado, que impulsiona a criação das inovações } \\
\text { científicas e o desenvolvimento das novas tecnologias. }\end{array}$ \\
\hline Educacional & $\begin{array}{l}\text { Refere-se aos processos formais e informais de aprendizagem } \\
\text { permanente ao longo da vida, do "saber pensar", que permitem ao } \\
\text { sujeito questionar, reconstruir e internalizar os padrões que governam e } \\
\text { controlam a informação na sociedade contemporânea. }\end{array}$ \\
\hline Cidadã & $\begin{array}{l}\text { "Refere-se à ampliação das possibilidades de exercício dos direitos a } \\
\text { partir das experiências positivas com o acesso e o uso de informações." } \\
\text { (MOURA, 2011, p. 54). }\end{array}$ \\
\hline Ética & $\begin{array}{l}\text { Refere-se aos fins para os quais a informação é usada na sociedade. Se é } \\
\text { usada para legitimar prepotências individuais e/ou coorporativas ou se é } \\
\text { usada para o bem comum. }\end{array}$ \\
\hline
\end{tabular}

Quadro 1:Abordagens da cultura informacional Fonte: ARAÚJO, 2011. 
Cabe ressaltar que as abordagens acima assinaladas são interdependentes, e a exposição separadamente é apenas para fins de ordenação e detalhamento. A Figura 1 representa a interligação conceitual das abordagens assinaladas.

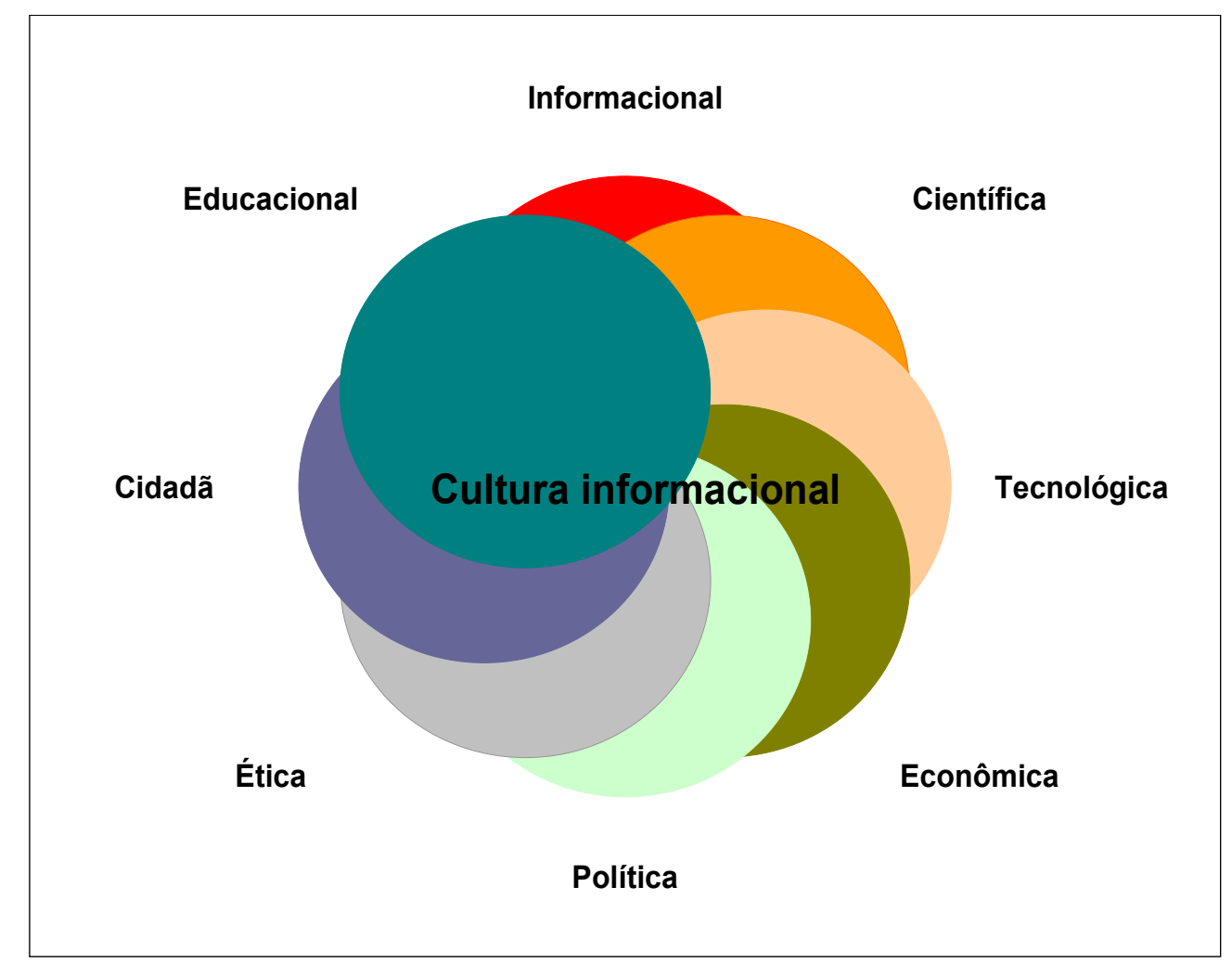

Figura 1:Cultura informacional e suas abordagens Fonte: ARAUJO, 2011.

Acredita-se que estudar a cultura significa "estudar um código de símbolos partilhados pelos membros dessa cultura" (LARAIA, 2001, p. 62-63). No caso da pesquisa realizada, estudaram-se as representações compartilhadas pelos sujeitos (alunos, professores e tutores) envolvidos na modalidade de educação a distância $(\mathrm{EaD})$. Na pesquisa, entre outros aspectos da $\mathrm{EaD}$, foram estudadas as representações sociais sobre educação, ciência, informação e conhecimento, tendo em vista a compreensão da interação entre esses elementos na composição das abordagens que articulam a cultura informacional. Foram adotadas como referencial teórico a Teoria das Representações Sociais e a técnica do Discurso do Sujeito Coletivo (DSC), desenvolvida por Lefevre e Lefevre. 


\section{TEORIA DAS REPRESENTAÇÕES SOCIAIS}

As representações sociais são elementos simbólicos expressos mediante o uso de palavras e de gestos para explicitar o que pensamos. São constituídas por "informações, imagens, crenças, valores, opiniões, elementos culturais, ideológicos etc.” (JODELET, 2001, p. 38). É por meio das representações que formulamos opiniões sobre determinado fato, objeto, pessoa. Essas representações baseiam-se sempre nas expectativas que desenvolvemos a respeito de objetos ou situações, ou seja, estão "ancoradas no âmbito da situação real e concreta dos indivíduos que as emitem" (FRANCO, 2004, p. 170). Podem ser entendidas como uma forma de construir e representar a realidade social. Possuem relações com a linguagem, a ideologia e o imaginário social e são socialmente construídas. Têm o papel de orientar as condutas, os comportamentos e as práticas sociais e culturais dos indivíduos (ALVES-MAZZOTTI, 1994, p. 60).

A cultura coletiva - que inclui os valores, as normas -, a comunicação e a linguagem (interpessoal, institucional e midiática), e a inserção socioeconômica, institucional, educacional e ideológica são consideradas elementos fundamentais das condições de produção e circulação de representações sociais (JODELET, 2001).

Jodelet (2001, p. 22) caracteriza as representações sociais como "uma forma de conhecimento, socialmente elaborada e partilhada, com um objetivo prático, e que contribui para a construção de uma realidade comum a um conjunto social". Para essa autora, alguns elementos e relações são fundamentais para a compreensão das representações sociais:

- $\quad$ uma representação é sempre de alguém (sujeito) sobre alguma coisa (objeto);

- $\quad$ a representação mantém com seu objeto uma relação de simbolização e de interpretação;

- $\quad$ é uma forma de saber, ou seja, a representação é como um modelo do objeto representado;

- $\quad$ esse saber é um saber prático que se refere à experiência a partir da qual ele é produzido, aos contextos e condições aos quais ele está submetido;

as representações sociais dos objetos passam por um processo de formação fundamentado por informações, experiências, conhecimentos e modelos, que, recebidos e transmitidos pela cultura e pela comunicação social, circulam na sociedade (PINHEIRO, 2008). 
A Teoria das Representações Sociais (TRS) surgiu nos anos de 1960 como uma vertente da Psicologia Social. As concepções iniciais que deram origem à teoria foram elaboradas por Serge Moscovici em 1961, na obra La Psychanalyse, sonimage, son public. A TRS é usada para explicar os fenômenos humanos a partir de uma perspectiva coletiva, mas sem perder de vista as individualidades. Representa tanto o conhecimento de senso comum, ou popular, como o do contexto sociocultural em que os indivíduos estão inseridos (FRANCO, 2004). Nesse sentindo, operacionaliza um conceito para trabalhar com o pensamento social, permitindo relacionar as interações sociais, os processos simbólicos e as condutas sociais, sem perder a sua dinâmica e diversidade (ALVES-MAZZOTTI, 1994; ARRUDA, 2002).

As representações se baseiam nas expectativas que os sujeitos desenvolvem a respeito de um objeto ou situação. Dessa forma, podemos dizer que, em nosso contexto de análise, os discursos expressos pelos alunos, tutores e professores foram pautados pelas expectativas que eles têm sobre os assuntos questionados no contexto da educação a distância.

Para compreender as representações enquanto produto, ou seja, pensamentos sociais, deve-se procurar

apreender seu conteúdo e sentido através de seus elementos constitutivos: informações, crenças, imagens, valores, expressos pelos sujeitos e obtidos por meio de questionários, entrevistas, observações, análise de documentos. (ALVESMAZZOTTI, 1994, p. 70).

\section{DISCURSO DO SUJEITO COLETIVO}

O Discurso do Sujeito Coletivo (DSC) "é uma proposta de organização e tabulação de dados qualitativos de natureza verbal, obtidos de depoimentos, artigos de jornais, matérias de revistas semanais, cartas, papers, revistas especializadas, etc.” (LEFEVRE; LEFEVRE, 2005, p. 16). A metodologia do DSC possibilita maior objetividade no processo de interpretação dos dados de pesquisa qualitativa, fundamentados na Teoria das Representações Sociais. Além disso, favorece a construção de discursos que representam as vozes do grupo de indivíduos sob estudo (DUARTE; MAMEDE; ANDRADE, 2009, p. 625-626).

Segundo Almeida (2005, p. 75-76):

As pesquisas sociais da Ciência da Informação que têm o processo de informação como foco seriam potencializadas com o uso da técnica DSC, visto que o pensamento coletivo pode ser resgatado sem os constrangimentos comuns às formas de categorizar a realidade. 
Os principais operadores metodológicos da técnica do DSC são: as "expressõeschave", as "ideias centrais" e/ou a "ancoragem" e os "discursos do sujeito coletivo".

As expressões-chave (ECH) são pedaços, trechos ou transcrições literais dos discursos que expressam os principais conteúdos das respostas e revelam a essência do depoimento. São com as expressões-chave que se constroem os DSC (LEFEVRE; LEFEVRE, 2005).

As ideias centrais (IC) são expressões linguísticas que nomeiam o sentido de cada depoimento. Descrevem, da maneira mais sintética, precisa e fidedigna possível, o sentido de cada um dos discursos analisados (LEFEVRE; LEFEVRE, 2005).

Ancoragem (AC) "é a manifestação linguística explícita de uma dada teoria, ou ideologia, ou crença que o autor do discurso professa" (LEFEVRE; LEFEVRE, 2005, p. 17).A ancoragem é considerada como um operador do DSC, porque algumas expressõeschave, em vez de se remeterem a uma ideia central correspondente, se remetem à figura metodológica da Teoria da Representação Social: a ancoragem.

O Discurso do Sujeito Coletivo (DSC) é o discurso único, redigido na primeira pessoa do singular, que reúne os conteúdos de depoimentos que possuem um sentido semelhante e/ou complementar.

A elaboração do DSC é realizada em seis etapas, as quais podem ser resumidas assim: 1) análise isolada de todas as respostas de cada uma das questões desenvolvidas ao longo da pesquisa; 2) destaque das expressões-chave das ideias centrais; 3) identificação e redação das ideias centrais e das ancoragens, se estas existirem ou puderem ser identificadas na superfície do texto; 4) sinalização dos extratos do texto com identificação (exemplo A, B) das ideias centrais e das ancoragens com sentido semelhante, equivalente e/ou complementar, para, posteriormente, serem agrupadas; 5) agrupamento das categorias identificadas; e 6) elaboração dos DSC com as expressões-chave pertencentes à mesma categoria (ALMEIDA, 2005).

Segundo Lefevre e Lefevre (2005, p. 19-20):

Através do modo discursivo, é possível visualizar melhor a representação social na medida em que ela aparece não sob uma forma (artificial) de quadros, tabelas e categorias, mas sob uma forma (mais viva e direta) de um discurso, que é, como se assinalou, o modo como os indivíduos reais, concretos pensam.

Entretanto, a construção de DSC não implica na ausência do pesquisador na condução dos propósitos da pesquisa. Trata-se, antes, de um recursometodológico que permiteapresentar demodo articulado as regularidades e as discrepâncias dos discursos pactuados coletivamente. 


\section{PERCURSO METODOLÓGICO E CARACTERIZAÇÃO DA AMOSTRA}

As representações sociais sobre informação e conhecimento apresentadas neste artigo são parte dos resultados da pesquisa de mestrado, que buscou investigar a cultura informacional no âmbito da educação a distância. Trata-se de uma pesquisa que se insere no nível descritivo das representações sociais em contextos e circunstâncias específicas.

A educação a distância $(\mathrm{EaD})$ pode ser considerada uma educação planejada, na qual os conteúdos são sistematizados de forma a permitir a aprendizagem independente e flexível (autoestudo). Esses conteúdos são mediados por tecnologias de informação e comunicação (TICs), que permitem também a interação através do planejamento da distribuição e disponibilização dos fluxos informacionais entre os sujeitos envolvidos no processo de ensino-aprendizagem.

A pesquisa tomou por referência os discursos dos sujeitos envolvidos nos cursos de licenciatura em Ciências Biológicas, Matemática, Normal Superior/Pedagogia e Química, na modalidade a distância, da Universidade Federal de Minas Gerais (UFMG) ${ }^{3}$, e foi realizada em três fases.

Na primeira fase, realizou-se uma caracterização histórica e social dos polos de apoio presencial em que os cursos se realizam. Em 2010, esses cursos analisados eram oferecidos em polos de apoio presencial localizados em doze cidades do interior de Minas Gerais: Araçuaí, Buritis, Campos Gerais, Conceição do Mato Dentro, Conselheiro Lafaiete, Corinto, Formiga, Frutal, Governador Valadares, Montes Claros, Teófilo Otoni e Uberaba.

Na segunda fase,foram traçados o perfil dos alunos e suas representações sobre o curso e o polo ao qual estão vinculados, a partir dos dados coletados por meio de questionário eletrônico, respondido por 192 alunos dos quatro cursos.

$\mathrm{Na}$ terceira fase da pesquisa,foram feitos aprofundamento e verticalização qualitativa dosdiscursos. Segundo Minayo (2001, p. 23), a pesquisa qualitativa "trabalha com o universo de significados, motivos, aspirações, crenças, valores e atitudes, o que corresponde a um espaço mais profundo das relações, dos processos e dos fenômenos que não podem ser reduzidos a operacionalização de variáveis". Nessa fase, participaram alunos, professores e

\footnotetext{
${ }^{3}$ A Universidade Federal de Minas Gerais (UFMG) faz parte do sistema Universidade Aberta do Brasil (UAB) como umas das Instituições de Ensino Superior (IES) que oferecem cursos superiores na modalidade a distância. A instituição oferece cursos de graduação (licenciatura e bacharelado), especialização e extensão.
} 
tutores. Essa opção refere-se à necessidade de compreender a interação e o fluxo informacional entre esses sujeitos no contexto do curso em que estão envolvidos.

A amostra da terceira fase da pesquisa contou com 33 participantes, entre alunos, professores e tutores vinculados aos cursos de licenciatura em Ciências Biológicas e Matemática da modalidade a distância da UFMG. A amostra de alunos foi composta por acessibilidade, formada por quinze alunos que tinham participado da segunda etapa e se dispuseram a participar respondendo ao questionário aberto eletrônico. A amostra de professores e tutores a distância foi composta intencionalmente. Devido aos objetivos da pesquisa, definimos que os coordenadores dos dois cursos deveriam ser entrevistados. Os professores dos cursos foram selecionados levando-se em consideração odepartamento, o grau de envolvimento com os cursos e a disponibilidade para participar da pesquisa. Foram entrevistados quatro professores, dois de cada curso, incluindo os coordenadores. Com relação aos tutores a distância, os critérios foram: tempo deatividade na tutoria e disponibilidade para participar. Foram entrevistados quatro tutores a distância, sendo dois de cada curso. A amostra de tutores presenciais foi composta por acessibilidade, ou seja, pelos dez tutores que sedispuseram a participar da pesquisa depois de receberem o convite com o link do questionário aberto. Convite esseque foi enviado para o e-mail de todos os tutores presenciais dos dois cursos.

Por uma questão de operacionalidade da pesquisa, os professores, coordenadores e tutores a distância que estavam acessíveis presencialmente foram entrevistados, sendo a entrevista gravada e posteriormente transcrita. Já os alunos e os tutores presenciais vinculados aos polos em que os cursos se realizam responderam a um questionário aberto eletrônico.

Sabe-se que os depoimentos coletados por meio de entrevista e de questionário aberto apresentam especificidades. Os discursos diretos tendem a ser mais ricos em detalhes e expressam uma opinião, digamos, espontânea dos sujeitos. Por outo lado, são mais suscetíveis a sofrer influências do pesquisador. Já os discursos escritos são mais sintéticos e, por vezes, incompletos ou/e não originais. Além disso, não há, por parte do pesquisador, controle sobre as condições de registro dos discursos.

Em virtude disso, os discursos coletivos produzidos não tiveram a intenção de serem conclusivos em relação ao fenômeno estudado, mas acredita-se que foram um suporte fundamental na compreensão da dinâmica de constituição da cultura informacional em ambientes acadêmicos atravessados pelo imperativo tecnológico e pela redução do rituais educacionais sincrônicos. 
Os participantes da pesquisa foram identificados da seguinte forma: alunos: A1, A2, ..., A15; professores: P1, P2, P3 e P4; tutores a distância: TD1, TD2, TD3 e TD4; tutores presenciais: TP1, TP2, ..., TP10.

Para operacionar o processo de construção dos discursos, usamos o softwareQualiQuantSoft, desenvolvido pela Sales \& Paschoal Informática (SPI), baseado no método do DSC.

\section{APRESENTAÇÃO E ANÁLISE DOS DISCURSOS DO SUJEITO COLETIVO}

Devido às características dos sujeitos e dos métodos de coleta de dados usados na pesquisa, optou-se por dividir os sujeitos em dois grupos.

Grupo 1 - Formado pelos professores, coordenadores e tutores a distância. Esses sujeitos foram entrevistados pessoalmente. São os sujeitos que estão mais próximos da instituição e, portanto, mais próximos uns dos outros. Convivem e atuam também nos cursos presenciais, e, de alguma forma, isso influencia na formação de seus discursos.

Grupo 2 - Formado pelos tutores presenciais e alunos. Esse grupo respondeu ao questionário eletrônico com questões abertas. Esses sujeitos estão distantes geograficamente da instituição mantenedora dos cursos e entre si, por atuarem em municípios diferentes.Trazem nos seus discursos a marca histórica, social e cultural da sua região.

\subsection{Representações sociais sobre o conceito de informação}

O conceito de informação é "muito complexo e engloba muitas definições e interpretações, dependendo sempre da área de conhecimento na qual se insere" (DUDZIAK, 2003, p. 23). Mesmo dentro do campo da Ciência da Informação, as discussões apresentam diferentes formulações. Do ponto de vista social, têm por base a compreensão "de que a informação na contemporaneidade constitui o instrumento chave para a inserção dos sujeitos, para a transformação da realidade, bem como fator crucial para a produção." (REIS, 1999, p. 152).

Conforme Reis et al. (2011, p. 17 ):

[...] obter/ter informação é uma prática social e implica em uma atitude e ação do sujeito, visando responder seus questionamentos e indagações a fim de se situar no mundo, podendo, por seu posicionamento, contribuir para manter ou produzir mudança no contexto da sociedade. 
Segundo Cardoso (1996, p. 71), ao longo da história, o conceito de informação sofreu“tantas modificações em sua acepção, que na atualidade seu sentido está carregado de ambiguidade: confundido, frequentemente, com comunicação, outras tantas com dado, em menor intensidade com instrução, mais recentemente com conhecimento".

\begin{abstract}
Quando refletimos sobre informação podemos perceber que ela possui duas dimensões intrinsecamente conectadas: a pessoal e a coletiva. A dimensão pessoal da informação manifesta-se pelo acervo de soluções e interpretações que acumulamos no desenrolar de nossa biografia, através daquilo que experienciamos e que nos fornece pistas para lidarmos com novas experiências. A dimensão coletiva identifica-se com fragmentos do conhecimento produzido desde que o mundo é mundo, ou seja, as sistematizações e interpretações de experiências disponibilizadas socialmente, ainda que não se possa deixar de destacar que tal disponibilização ocorre diversamente entre os indivíduos em função dos diferentes lugares que ocupam na estrutura social. (CARDOSO, 1996, p. 71, grifos nossos).
\end{abstract}

As definições do conceito de informação presentes nos discursos foram agrupadas em cinco categorias, mas duas dessas categorias foram expressas apenas pelo Grupo 2. O Quadro 2 apresenta essas categorias e os respectivos DSC elaborados com as expressões-chave semelhantes e/ou complementares.

\begin{tabular}{|c|c|}
\hline Categoria & $\overline{D S C}$ \\
\hline $\begin{array}{l}\text { A - } \\
\text { Informação } \\
\text { como tudo } \\
\text { que pode ser } \\
\text { divulgado, }\end{array}$ & $\begin{array}{l}\text { GRUPO } 1 \text { - Informação é tudo que pode ser divulgado, socializado, por algum meio, } \\
\text { seja escrito, áudio ou visual. Qualquer tipo de conhecimento, qualquer tipo de coisa, } \\
\text { qualquer anunciado, qualquer tipo de observação que se faça, e essa observação é } \\
\text { transmitida às outras pessoas. Informação seria um conhecimento que a gente recebe. } \\
(P 3, T D 4, T D 3, T D 2)\end{array}$ \\
\hline $\begin{array}{l}\text { compartilhado } \\
\text { pelas pessoas }\end{array}$ & $\begin{array}{l}\text { GRUPO } 2 \text { - Tudo que é passado de uma pessoa para outra, uma comunicação, } \\
\text { transmissão de dados. }(A 5, A 12, T P 3)\end{array}$ \\
\hline
\end{tabular}

GRUPO 1 - Informação, para mim, é toda vez que você tem um dado que modifica o conhecimento de alguém. Só existe informação se houver mudança de conhecimento,

B -

Informação como algo que modifica e permite a construção de conhecimento humano se aquele dado ajudar a mudar o conhecimento de alguém. Se não muda, não é informação, é dado. Eu diria que informação é o conjunto de elementos disponíveis num determinado meio para tornar possível a "apreensão" da realidade. Esta informação só vai nos permitir conhecimento se ela for tratada com determinado tipo de instrumento. $E^{\prime}$ algo produzido por outra pessoa. Então a pessoa que vai ter acesso a essa informação, ela vai ver como algo externo e dai ela pode internalizar aquilo e aquilo virar conhecimento e saber,porque é através da informação que a gente passa a conhecer algo que a gente não viu e aquilo, de certa forma, começa a fazer uma diferença na nossa forma de ver a vida. Pode ser algo que você já sabe, mas está completando a sua formação. Algo que você não sabe, mas você acaba ali sabendo. Mas informação não é só saber os fatos. É saber contextualizá-los. (P1, TD3, TD1, TD2, P2, P4) 
GRUPO 2 - Tudo aquilo que conseguimos captar é informação. Não vivemos sem ela tão pouco ela existiria se não fosse nós, seres humanos, para captá-la. É uma relação de dados que, ao serem processados e organizados corretamente, contribuem para o conhecimento. É o resultado do processamento, manipulação e organização de dados, de tal maneira que represente modificações no conhecimento prévio adquirido. Então, é uma forma/modelo de adquirir conhecimento, ou seja, uma fonte de conhecimento. É tudo que, de algum modo, acrescenta e nos dá conhecimento e cultura. (A1, A15, TP1, A11, A12, TP7, A7)

C -

Informação como notícia, novidade, divulgada pela mídia

GRUPO 1 - A informação é interessante justamente pela liberdade de imprensa. A gente pode ouvir um monte de coisas, um monte de informações e poder julgar qual delas é mais relevante para nosso desenvolvimento, no nosso contexto, e cada vez a gente tem informação sobre o que está acontecendo mais distante. (TD1, P4)

GRUPO 2 - Penso que informação é tudo aquilo que a imprensa, a mídia, os veículos de comunicação nos passam. Tudo aquilo que é novo. (A4, A6)

D GRUPO 2 - A informação assume, hoje em dia, uma importância crescente. Ela torna-se

Informação fundamental. É algo muito importante em nossos dias. Informação é um insumo para como uma tomada de decisão e criação de oportunidades. É tudo que, de algum modo, facilita e coisa útil ajuda a esclarecer conceitos, dúvidas, problemas. É a resposta às minhas dúvidas, esclarecimento que pode ser guardado para possíveis utilizações posteriores. (TP1, TP14, TP10, A7, TP6, A10, A9)

E -

Informação no sentido de ter

GRUPO 2 - São conhecimentos sobre um determinado assunto, ou seja, tudo que sabemos sobre algo. Informação é você ter em mãos aquilo que você tem dúvida ou não conhece. Pode ser instruções positivas ou negativas de situações as quais vivenciamos conhecimento direta ou indiretamente. É conhecimento. (A13, A8, TP4, TP5, TP9, TP10)

sobre algo

Quadro 2:Representações sociais sobre o conceito de informação

Fonte: ARAUJO, 2011.

$\mathrm{Na}$ ideia central que considera a informação como tudo que pode ser divulgado, transmitido, compartilhado pelas pessoas, para o Grupo 1, informação é qualquer tipo de conhecimento,qualquer anunciado, qualquer tipo de observação realizada e transmitida às outras pessoas. Numa perspectiva semelhante, o Grupo 2 representa a informação como tudo que é passado de uma pessoa para outra, ou seja, uma comunicação. Em ambos os grupos, o foco da representação da informação está no processo de intermediação da comunicação entre os sujeitos sociais.

\begin{tabular}{llcc}
\hline & \multicolumn{1}{c}{ CATEGORIAS } & Freq. & $\%$ \\
\hline \multirow{2}{*}{$\mathbf{A}$} & $\begin{array}{l}\text { Informação como tudo que pode ser divulgado, transmitido, } \\
\text { compartilhado pelas pessoas }\end{array}$ & 7 & 18,42 \\
\hline \multirow{2}{*}{$\mathbf{B}$} & $\begin{array}{l}\text { Informação como algo que modifica e permite a construção de } \\
\text { conhecimento humano. }\end{array}$ & 14 & 36,84 \\
\hline $\mathbf{C}$ & Informação como notícia, novidade, divulgada pela mídia & 4 & 10,53 \\
\hline $\mathbf{D}$ & Informação como uma coisa útil & 7 & 18,42 \\
\hline $\mathbf{E}$ & Informação no sentido de ter conhecimento sobre algo & 6 & 15,79 \\
\hline & TOTAL DE RESPOSTAS DA PERGUNTA & $\mathbf{3 8}$ & \\
\hline
\end{tabular}

Tabela 1:Distribuição das ideias centrais sobre o conceito de informação

Fonte: ARAÚJO, 2011. 
$\mathrm{Na}$ ideia central que percebe a informação como algo que modifica e permite a construção do conhecimento, o DSC do Grupo 1evidencia que há informação se houver mudança de conhecimento, se aquele dado ajudar a mudar o conhecimento de alguém.

O DSC do Grupo 2ressalta que tudo aquilo que conseguimos captar é informação. A informação é compreendida como um fenômeno humano e se aproxima do entendimento de informação enunciado por Cardoso (1996). A citada representação recebeu o maior número de respostas, conforme a Tabela 1. Para os sujeitos que compartilham dessa representação, a informação relaciona-se à produção de sentido.

A ideia central que representa a informação como notícia é expressa por $10,53 \%$ das respostas (Tabela 1). No Grupo 1, o DSC se refere a liberdade de impressa e sugere que a informação está relacionada com as notícias que a impressa divulga e que podem contribuir para a formação de nossa visão de mundo. Já no Grupo 2, o DSC acredita que a informação é tudo aquilo que a imprensa, a mídia, os veículos de comunicação divulgam. Em ambos os grupos, a ideia de informação como novidade fica subjacente aos discursos.

A informação como uma coisa útil foi expressa pelo Grupo 2, ou seja, por alunos e tutores presenciais. A ideia central desse DSC é o fato de a informação ser usada pararesolver problemas e esclarecer dúvidas.

Outra representação sobre informação expressa apenas pelo Grupo 2 é a informação no sentido de obter conhecimento sobre algo, ou seja, a informação é vista como os conhecimentos sobre um determinado assunto e é representada como tudo que sabemos sobre algo.

\subsection{Representações sociais sobre o conceito de conhecimento}

No sentido amplo, o conhecimento é tudo que consideramos como real e verdadeiro. É socialmente construído, moldado pela cultura e pelos sistemas sociais (JOHNSON, 1997; DEMO, 1999). Essa noção encerra a dimensão de que o conhecimento é algo construído pelos indivíduos a partir de suas capacidades e condições de processamento, interpretação e compreensão da informação e considera o contexto social em que está inserido.

Para Demo (1999, p. 299), as características do conhecimento podem ser resumidas da seguinte forma:

a) conhecimento pode ser o distintivo principal do ser humano, como dizem muitas teorias da aprendizagem, bem como a tradição da filosofia: homo animal rationale, ou seja, o que melhor o distingue dos outros seres é a capacidade de conhecer ou de aprender; 
b) conhecimento pode ser virtude do ser humano, quando comparece com alavanca central da emancipação, em particular como estratégia de superação da pobreza política;

c) conhecimento pode ser o método central de análise da realidade, conferindo ao ser humano a condição de intervenção consciente e competente;

d) conhecimento pode ser a ideologia com base científica a serviço da elite e/ou da comparação dos cientistas, sobretudo quando se vende como isenta de valores;

e) conhecimento pode ser a artimanha do ser humano, quando constrói consciência crítica para deturpá-la nos outros, usando ciência apenas em sentido estratégico;

f) conhecimento pode ser a perversidade do ser humano, quando é feito e usado para fins de destruição.

As representações sociais sobre o conceito de conhecimento foram agrupadas em duas grandes categorias. O Quadro 2 mostra as categorias e os respectivos DSC construídos com as expressões-chave de cada uma delas.

$\mathrm{Na}$ categoria conhecimento como processo,o DSC do Grupo 1 considera que o conhecimento é o modo por meio do qual as pessoas internalizam a informação e atribuem significados a ela,ou seja, o conhecimento é a informação socialmente trabalhada. Na mesma linha de pensamento, o DSC do Grupo 3 representa o conhecimento como uma forma de aquisição de aprendizado,ou seja, é conhecer o que antes não se conhecia e transformar sua forma de pensar e agir. Nessa categoria, os DSC evidenciam o conhecimento como um processo de aprendizagem, um modo de processamento de informações que permite a construção do conhecimento.

Já na categoria que reúne as ideias centrais sobre o conhecimento como produto, o Grupo 1 representa o conhecimento como aquilo que as sociedades produzem, com vistas a entender melhor o contexto social em que vivem, e incorpora a compreensão e o papel da língua, da natureza, da histórianesse processo. ODSC sugerequeoconhecimento pode ser formado por ideias,conclusões úteis, informações corretas que o processamento mental permite construir. O Grupo 2 diz que o conhecimento é um conjunto de múltiplas informações e saberes que podem ser extraídos de fontes de informação e podem ser utilizados de forma concreta no diaadia. Esse discurso remete à concepção de conhecimento como informação registrada. 


\begin{tabular}{|c|c|}
\hline Categoria & DSC \\
\hline $\begin{array}{l}\text { A - } \\
\text { Conhecimento } \\
\text { como } \\
\text { processo: uma } \\
\text { forma de }\end{array}$ & $\begin{array}{l}\text { GRUPO } 1 \text { - Conhecimento é o estudo, é analisar as coisas, obter informações. É um } \\
\text { modo particularmente metódico de se tratar as informaçõespara nos permitir } \\
\text { apropriar determinada realidade, nos permitir conhecer determinada realidade. É o } \\
\text { modo pelo qual as pessoas internalizam a informação e garantem significados a ela. É } \\
\text { um conjunto de relações que o indivíduo tem, formando um esquema na cabeça dele. } \\
\text { Um esquema formado de conceitos e relações e sua aplicação. Como é que ele utiliza } \\
\text { esse conhecimento. Assim, conhecimento é a informação trabalhada.Depende da } \\
\text { educação e depende da capacidade de assimilar as informações e aproveitá-las. } \\
\text { Processá-las de uma forma que a gente vai gerar alguma coisa que possa ser passada, } \\
\text { transmitida. (TD4, P2,TD3, P1, P4) }\end{array}$ \\
\hline
\end{tabular}

processamento mental de informações, uma forma de aprendizagem

GRUPO 2 - Conhecimento é o ato ou efeito de retirar a essência de um problema ou situação. É uma forma de aquisição de aprendizado. É conhecer o que antes não se conhecia e transformar sua forma de pensar e agir. É saber identificar e procurar respostas no lugar certo a partir de uma nova maneira de pensar. É a disposição para pesquisar, tirar dúvidas, aprender e colocar em prática. É ter embasamento para a criticidade ou para buscar esclarecimentos a partir de questionamento. $E$ o aperfeiçoamento do que já sabe e descobrimento de coisas novas. É o conjunto de informações absorvidas no processo de aprendizado para a construção do "saber". Para atingir o conhecimento, é preciso empenho, pois o conhecimento se constrói. (TP1, A1, A10, A11, A3, A7, TP5, A5, TP6, A9, A14)

GRUPO 1 - Conhecimento é aquilo que as sociedades produzemcom vistas a entender melhor a sociedade que ela vive, a língua que elas falam, a natureza, a história, o mundo que elas vivem. Seria uma informação que a gente recebe, entende e consegue passá-la de forma correta. É a possibilidade de formar a nossa opinião enquanto cidadão, enquanto um ser conhecedor de várias posições, de várias coisas. (P3, TD1,

B TD2)

Conhecimento como produto: os saberes, as ideias, as informações que adquirimos ao longo da vida
GRUPO 2 - Conhecimento são as ideias adquiridas no decorrer da vida, desde o nascimento, ao longo do tempo, vindas de gerações anteriores ou de pessoas de ensino qualificado. É tudo aquilo de útil que aprendemos, seja via internet, jornais, televisão, da forma que for. Tudo aquilo que engloba um conhecimento novo, uma ideia ou noção de alguma coisa. $O$ que buscamos nos livros ou em outras mídias e no nosso dia a dia. É a ideia ou conclusão que tiramos de alguma coisa ou alguém. Significa entender sobre determinado assunto, ou seja, é aquilo que se sabe. Conhecimento é um conjunto de múltiplas informações, um conjunto de saberes que podem ser extraídos de fontes de informação e podem ser utilizados de forma concreta no diaadia. Tudo que seja útil a nossa formação moral é uma forma de conhecimento. É o agente transformador de um individuo e consequentemente de uma sociedade. Coloca-nos à disposição para resolver problemas do mundo e da vida humana. (A12, A8, A4, TP1, A6, A7, A8, TP1, A13, A14, TP9, TP10, TD15, TP3)

Quadro 3:Representações sociais sobre o conceito de conhecimento

Fonte: ARAUJO, 2011.

A Tabela 2 indica a distribuição de ideias centrais semelhante entre as duas categorias. Os DSC evidenciam que essas duas categorias são complementares, uma vez que a produção social do conhecimento tem como condições fundamentais o processamento e a organização da informação. 


CATEGORIAS $\quad$ Freq. $\%$

\begin{tabular}{clcc}
\hline A & $\begin{array}{l}\text { Conhecimento como processo: uma forma de processamento mental } \\
\text { de informações, uma forma de aprendizagem }\end{array}$ & 16 & 48,48 \\
\hline B & $\begin{array}{l}\text { Conhecimento como produto: os saberes, as ideias, as informações } \\
\text { que adquirimos ao longo da vida }\end{array}$ & 17 & 51,52 \\
\hline & TOTAL DE RESPOSTAS DA PERGUNTA & $\mathbf{3 3}$ & \\
\hline
\end{tabular}

Tabela 2:Distribuição das ideias centrais sobre o conceito de conhecimento

Fonte: ARAUJO, 2011.

\section{CONSIDERAÇÕES FINAIS}

O estudo desenvolvido permitiu compreender o vigor da Teoria das Representações Sociais e suas contribuições e aos estudos desenvolvidos no campo da Ciência da Informação. Com o apoio da referida teoria, foi possível identificar as representações sociais dos sujeitos envolvidos na modalidade de educação a distância em relação aos conceitos de informação e conhecimento. Conforme salientado, trata-se de mecanismos de composição, ajustamento e difusão do senso comum sobre distintos aspectos da vida social, valores embutidos na fala e nas crenças de um determinado grupo.

Nesse contexto, a técnica do Discurso de Sujeito Coletivo se mostrou bastante eficiente para a organização e apresentação dos dados sobre representações sociais obtidos ao longo do desenvolvimento da pesquisa.

Considerando que o acesso à educação é um elemento fundamental para o desenvolvimento da cultura de modo geral, pode-se dizer que a construção da cultura informacional na sociedade da informação depende da expansão da educação e do acesso a ela. Assim, representações sociais sistematizadas no Discurso do Sujeito Coletivo realizado permitiram-nos chamar a atenção para a importância do discurso do cidadão comum na compreensão da realidade social e na construção e consolidação de teorias.

Com relação à informação, a variedade de representações sociais sobre o tema corrobora o fato de esse conceito ser mesmo bastante complexo. A representação social mais significativa na população estudada percebe a informação como algo que modifica o conhecimento e permite a construção dele. Nesse aspecto, a representação social produzida identifica o conhecimento como um processo de aprendizagem.

$\mathrm{Na}$ mesma perspectiva, a representação social que considera a informação como os conhecimentos adquiridossobre determinado assunto sugere que a informação e o conhecimento são fenômenos humanos interrelacionados. A informação é a base para a 
construção do conhecimento, enquanto que o conhecimento sistematizado é a informação compartilhada entre os sujeitos.

\section{REFERÊNCIAS}

ALMEIDA, Carlos Cândido de Almeida. Discurso do sujeito coletivo: reconstruindo a fala do social. In: VALENTIM (Org). Métodos qualitativos de pesquisa em Ciência da Informação. São Paulo: Polis, 2005, cap. 3, p. 59-79

ALVES-MAZZOTTI, Alda Judith. Representações sociais: aspectos teóricos e aplicações à educação. Em Aberto, Brasília, v. 14, n. 61, jan./mar. 1994, p. 60-78. Disponível em: $<$ http://www.rbep.inep.gov.br/index.php/emaberto/article/viewFile/912/818>. Acesso em: 19 nov. 2009.

ARAUJO, Sinay Santos Silva de. Cultura informacional, representações sociais e educação a distância: um estudo de caso da EaD na UFMG. 2011. 235f. Dissertação (Mestrado em Ciência da Informação) - Escola de Ciência da Informação, Universidade Federal de Minas Gerais - UFMG, Belo Horizonte, 2011.

ARRUDA, angela. Teoria das representações sociais e teorias de gênero. Cadernos de Pesquisa, n. 117, p. 127-147, nov./2002. Disponível em: $<$ http://www.scielo.br/pdf/cp/n117/15555.pdf>. Acesso em: 19 nov. 2009

CARDOSO. Ana Maria Pereira. Pós-modernismo e informação: conceitos complementares? Perspectivas em Ciência da Informação, Belo Horizonte, v. 1, n. 1, p. 63-79, jan./jun. 1996. Disponível

$<$ http://portaldeperiodicos.eci.ufmg.br/index.php/pci/article/viewFile/241/28>. Acesso em: 26 nov. 2009

CHAVES FILHO, Hélio. A Universidade Aberta do Brasil: estratégia para a formação superior na modalidade de EAD. Fonte, Belo horizonte, jan./jun. 2007 p. 85-91

DEMO, Pedro. Conhecimento Moderno: sobre ética e intervenção do conhecimento. 3. ed. Petrópolis: Vozes, 1999, 317 p.

DUARTE, Sebastião Junior Henrique; MAMEDE, Marli Villela; ANDRADE, Sônia Maria Oliveira de. Opções teórico-metodológicas em pesquisas qualitativas: representações sociais e discurso do sujeito coletivo. Saúde soc., v.18, n.4, dez./2009, p.620-626. Disponível em: $<$ http://www.scielo.br/pdf/sausoc/v18n4/06.pdf >. Acesso em: 20 ago. 2010.

DUDZIAK, Elisabeth Adriana. Informationliteracy: princípios, filosofia e prática. Ciência da informação[online], Brasília, v. 32, n. 1, p. 23-35, jan./abr. 2003. Disponível em: $<$ http://revista.ibict.br/index.php/ciinf/article/viewArticle/123>. Acesso em: 26 ago. 2010

ELIAS, Norbert. A sociedade dos indivíduos. Rio de Janeiro: Jorge Zahar, 1994. 201 p. 
FRANCO, Maria Laura Puglisi Barbosa. Representações sociais, ideologia e desenvolvimento da consciência. Cadernos de Pesquisa, v. 34, n. 121, jan./abr. 2004. Disponível em: $<$ http://www.scielo.br/pdf/cp/v34n121/a08n121.pdf>. Acesso em: 02 out. 2009.

GEERTZ, Clifford. A interpretação das culturas. 13. reimpr. Rio de janeiro: LTC, 1989. $213 \mathrm{p}$.

JODELET, Denise. Representações sociais: um domínio em expansão. In: . As representações sociais. Rio de Janeiro: EdUERJ, 2001, cap. 1, p. 17-44.

LARAIA, Roque de Barros. Cultura: um conceito antropológico, 14. ed. Rio de Janeiro: Zahar, 2001.

LEFEVRE, Fernando; LEFEVRE, Ana Maria Cavalcanti. O discurso do sujeito coletivo: um novo enfoque em pesquisa qualitativa (desdobramentos). 2. ed. Caixas do Sul, RS: EDUCS, 2005. 256 p.

MARTELETO, Maria Regina. Cultura informacional: construindo o objeto informação pelo emprego dos conceitos de imaginário, instituição e campo social. Ciência da Informação[online].v. $\quad 24, \quad \mathrm{n} . \quad 1, \quad$ p.1-8, $1995 . \quad$ Disponível em: $<$ http://revista.ibict.br/index.php/ciinf/article/view/535/487>. Acesso em: 26 jun. 2009

MINAYO, Maria Cecília de Souza (Org.). Pesquisa social: teoria, método e criatividade. 19. ed. Petrópolis: Vozes, 2001, 80 p. (Coleção temas sociais).

MORIN, Edgar. O método:4. asidéias: habitat, vida, costumes, organização. Porto Alegre: Sulina, 1998, $325 \mathrm{p}$.

MOSCOVICI, Serge. Representações sociais: investigações em psicologia social. 6. ed. Petrópolis, RJ. Vozes. 2009.

PINHEIRO, José Walber Borges. Alunos na educação a distância: representações sociais de alunos do sistema de educação a distância da Academia Nacional de Polícia. 2008. 108 f. Dissertação (Mestrado em Educação). Programa de Mestrado em Educação. Universidade Católica de Goiás. Goiânia, 2008. Disponível em: Disponível em: $<$ http://tede.biblioteca.ucg.br/tde_busca/arquivo.php?codArquivo=533 $>$. Acesso em: 20 ago. 2010 .

REIS, Alcenir Soares dos. Retórica-Ideologia-Informação: questões pertinentes ao cientista da informação? Perspectivas em Ciências da Informação, Belo Horizonte, v. 4, n. 2, p. 145 160, jul./dez.1999.

REIS, Alcenir Soares doset al. Informação e cidadania: conceitos e saberes necessários à ação. In: MOURA, Maria Aparecida (Org.). Cultura informacional e liderança comunitária: concepções e práticas. Belo horizonte: UFMG/PROEX, 2011, p.17-26.

SILVA, Armando Malheiro da. A informação: da compreensão do fenômeno e construção do objeto científico. Porto: Edições Afrontamento, 2006, 176 p. 